Thorax (1964), 19, 490.

\title{
A new terminology for the subdivision of atrial septal defects
}

\author{
E B B E A R N F R E D \\ From the Department of Surgery D, Rigshospitalet, University of Copenhagen, Denmark
}

To be of scientific value, a diagnostic terminology has to be clear, uniform, and unambiguous. This is especially true in heart surgery, where an exact pre-operative diagnosis is essential, and one must be able to fit this diagnosis into the terminological system of the disease.

The merging of a theoretical and a descriptive grouping, hitherto used in subdividing atrial septal defects, does not meet these demands.

\section{PRE-OPERATIVE DIAGNOSIS}

The diagnosis of an atrial septal defect is made by clinical assessment, radiological examinations, angiocardiography, electrocardiography, and heart catheterization including the determination of oxygen saturation, pressure measurements, possibly dye dilution curves, and observation of the catheter configuration.

The clinical examination gives no information regarding the size and site of the defect, and only when severe valvular lesions are present can a more accurate diagnosis be made in this way.

A radiological examination of the heart is of no value in determining the type of an isolated defect, neither is angiocardiography (Davidsen, 1960 ; Killen, Lance, and Adams, 1961), but in cases complicated by anomalous pulmonary drainage, one or more of the transposed veins may be disclosed on the radiographic screen (Lawrance, Grimshaw, Hoyle, Hicks, Nixon, and Wooler, 1962).

By electrocardiography, defects complicated by lesions in the mitral and tricuspid valves can be distinguished from other defects with a high degree of certainty by determining the electric axis of the QRS complex (Blount, Balchum, and Gensini, 1956; Burch and DePasquale, 1959 ; Arnfred, 1964); but this type of examination gives no help in subdividing the other groups.

Catheterization of the heart is the most valuable examination in the differentiation between isolated defects and the defects complicated by other anomalies, such as valvular malformations, ventricular septal defect (atrioventricular defects), and anomalous pulmonary drainage ; but catheteriza- $ᄋ$ tion often fails to disclose the site of the isolated defect (Arnfred, 1961; Killen et al., 1961 ; Arnfred, 1962).

Thus it appears that the pre-operative examination makes it possible to group atrial septal defects into four types: (1) isolated defects, (2) defects associated with anomalous pulmonary drainage, $\vec{\oplus}$ (3) defects combined with lesions of one or both + of the atrioventricular valves, and (4) atrioventricular defects.

\section{OPERATIVE FINDINGS}

During open-heart intervention, the size and the site of the defect are easily established, as are $\overrightarrow{0}$ other associated malformations; but when the defect is situated in the anterior part of the septum it may be difficult to determine whether the lesion is a primum defect with an intact septum intermedium or a secundum defect localized far anteriorly. Consequently, almost the same $\stackrel{\sim}{x}$ limitations are found in making an exact diag- $\frac{0}{3}$ nosis during operation as those which apply to the pre-operative examination.

\section{NEW TERMS}

To keep our diagnostic accuracy within the limits $\frac{7}{0}$ of practical possibilities the following subdivision of atrial septal defects is proposed:

ISOlATED ATRIAL SEPTAL DEFECT This is a defect situated in the interatrial septum and not complicated by other malformations. The pre-operative signs will be a normal or right axis deviation in the electrocardiogram and no disclosure of $\stackrel{\oplus}{\rightarrow}$ anomalous lung drainage by radiographic examination or by heart catheterization.

POSTERIOR COMPLICATED ATRIAL SEPTAL DEFECT This defect is complicated by partial or complete 
transposition of the lung veins, the pre-operative signs being a normal or right axis deviation in the electrocardiogram and positive findings of anomalous pulmonary drainage by radiography and/or by heart catheterization.

ANTERIOR COMPLICATED ATRIAL SEPTAL DEFECT This is a defect associated with lesions of one or both of the atrio-ventricular valves. Here the preoperative axis of the electrocardiogram is to the left; heart catheterization gives no evidence of a lesion in the ventricular septum.

ATRIO-VENTRICULAR DEFECT This defect includes parts of both the interatrial and the interventricular septum. The electric axis is to the left, and during catheterization the tip of the catheter may pass directly from one ventricle to the other.

This classification meets the requirements mentioned above: it divides the disease into groups which pre-operatively, as well as during operation, can easily be distinguished from each other. Moreover, it has the advantage of distinguishing the defects, which may be operated on by closed methods or by hypothermia, from those in which an open operation using extracorporeal circulation is indispensable. By using the terminology proposed, the existing confusion, especially regard- ing the classification of the so-called primum defects, could be eliminated.

\section{SUMMARY}

The author proposes a new classification of atrial septal defects: (1) isolated atrial septal defect; (2) posterior complicated atrial septal defect;

(3) anterior complicated atrial septal defect; and (4) atrio-ventricular defect. This classification is within the limits of diagnosis, both pre-operatively and during surgical intervention.

\section{REFERENCES}

Arnfred, E. (1961). Open heart surgery in atrial septal defect. Acta chir. scand. Suppl., 283, 57.

- (1962). Atrieseptumdefekt opereret med ekstrakorporal cirkulation. Nord. Med., 67, 856.

(1964). Surgical treatment of atrial septal defect of anterior type with the aid of extracorporeal circulation Acta. chir. scand. (in press).

Blount, S. G., Jr., Balchum, O. J. and Gensini, G. (1956). The persistent ostium primum atrial septal defect. Circulation, 13, 499.

Burch, G. E., and DePasquale, N. (1959). The electrocardiogram, and ventricular gradient in atrial septal defect. Amer. Heart $J$. 58, 191.

Davidsen, H. G. (1960). Atrial septal defect. Thesis. Munksgaard, Copenhagen

Killen, D. A., Lance, E. M., and Adams, J. E. (1961). The limitations of present techniques in the precise diagnosis of interatrial septal defects and description of an experimental method of defect visualization. $J$. thorac. cardiovasc. Surg., 41, 643.

Lawrance, K., Grimshaw, V. A., Hoyle, G., Hicks, J. P. N., Nixon, P. F. G., and Wooler, G. H. (1962). Surgical treatment of atrial septal defect and partial anomalous pulmonary venous drainage, Ibid., 43, 622. 